\title{
Persistencia de síntomas en pacientes con COVID-19
}

\author{
Persistence of symptoms in patients with COVID-19
}

\section{Comentado de:}

Carfi A, et al. JAMA. 2020 Jul 9;e2012603. PMID: $32644129^{1}$

\section{Objetivo}

Describir los síntomas persistentes en pacientes dados de alta luego de recuperarse de COVID-19.

\section{Diseño y lugar}

Serie de casos realizada en una institución hospitalaria universitaria en Roma, Italia, en la que había establecido un servicio de seguimiento de pacientes dados de alta luego de recuperarse de COVID-19, incluyendo a todos los pacientes que cumplieron con el criterio de la Organización Mundial de la Salud para discontinuar la cuarentena (afebril por tres días consecutivos, mejoría sintomática, dos pruebas negativas para SARS-CoV-2).

\section{Participantes}

Se incluyeron los pacientes en seguimiento post-alta de COVID-19 con resultado negativo de una nueva prueba de Reacción en Cadena de la Polimerasa (PCR, por sus iniciales en inglés) para SARS-CoV-2 realizada como criterio de selección para este estudio.

\section{Medición de resultados principales}

Se realizó una historia clínica detallada (antecedentes clínicos y farmacológicos, factores del estilo de vida, vacunación) y examen físico a todos los pacientes.

La evaluación de los síntomas potencialmente relacionados al COVID-19 se realizó con un cuestionario estandarizado que indagaba la presencia o ausencia de síntomas retrospectivamente y preguntaba si esos síntomas persistían al momento de la visita. Se podía reportar más de un síntoma.
Se utilizó la escala visual analógica del EuroQol para determinar la calidad de vida (valores entre 0 y 100). Se consideró que una diferencia de 10 puntos en la escala reflejaba un empeoramiento en la calidad de vida.

\section{Resultados principales}

De un total de 179 pacientes elegibles, 14 (8\%) rechazaron participar y 22 tuvieron un test positivo, lo que permitió incluir a 143 participantes con una edad media de 56,5 (Desvío estándar [DE] 14,6) años, de los cuales 53 (37\%) fueron mujeres.

Durante la hospitalización el $72,7 \%$ había tenido neumonía intersticial. La media de estadía hospitalaria fue 13,5 (DE 9,7) días; 21 pacientes (15\%) habían recibido ventilación no invasiva y 7 (5\%), ventilación invasiva.

Los pacientes fueron evaluados en promedio 60,3 (DE 13,6) días después del primer síntoma de COVID-19. Solo 18 (12,6\%) pacientes estaban libres de síntomas al momento de la evaluación; $32 \%$ de los participantes tenía uno o dos síntomas y $55 \%$, tres o más. Se observó un empeoramiento de la calidad de vida en $44,1 \%$ de los pacientes. Los síntomas persistentes más frecuentes fueron la fatiga $(53,1 \%)$, la disnea $(43,4 \%)$, el dolor articular $(27,3 \%)$ y el dolor torácico $(21,7 \%)$.

\section{Conclusiones}

En pacientes recuperados de COVID-19, 87,4\% reportó la persistencia de al menos un síntoma en el seguimiento posterior al alta. Es necesario continuar el monitoreo y los efectos a largo plazo en este grupo de pacientes.

Fuente de financiamiento/Conflicto de interés de los autores: No se informa la fuente de financiamiento. Los autores reportaron no tener conflictos de interés.

\section{Comentario}

Si bien el presente estudio es modesto, con un pequeño número de pacientes y sin un grupo control (por ej., pacientes dados de alta por otros motivos), aporta información valiosa sobre el seguimiento de pacientes con COVID-19 y muestra la persistencia de ciertos síntomas, principalmente la fatiga y la disnea, tras 60 días -en promedio- del inicio de la enfermedad. Artículos recientes alertan sobre la posibilidad de daño respiratorio a largo plazo. El estudio de Mo y col reportó que, en sobrevivientes dados de alta por COVID-19, la alteración de la capacidad de difusión es la anormalidad más común de la función pulmonar, seguida de los defectos ventilatorios restrictivos; ambos hallazgos estuvieron asociados con la gravedad de la enfermedad en su fase aguda ${ }^{2}$. Asimismo, otro estudio concluyó que el defecto respiratorio restrictivo y la disfunción respiratoria leve podrían ser persistentes en estos pacientes; la mayoría de los cuales presentaban anormalidades residuales en la tomografía de tórax, siendo la fibrosis pulmonar el patrón más común ${ }^{3}$.

Además, los pacientes gravemente enfermos con COVID-19 podrían presentar el síndrome post-cuidados intensivos, el cual engloba las secuelas físicas (principalmente, respiratorias y neuromusculares), cognitivas (alteraciones de la memoria y de la atención) y psíquicas (depresión, ansiedad, estrés y/o síndrome de estrés postraumático) tras el alta de las unidades de terapia intensiva, y que impactan negativamente en su calidad de vida ${ }^{4}$, aunque su incidencia no está bien establecida.

\section{Conclusiones de la comentadora}

En los últimos meses nos enfrentamos al desafío de una enfermedad nueva, y a medida que aumenten los casos y los pacientes recuperados, iremos observando sus consecuencias a largo plazo. Como médicos de atención primaria recibiremos consultas relacionadas con la persistencia de síntomas y debemos estar preparados para resolverlas y evaluarlas adecuadamente. Es necesario contar con estudios que sigan aportando información acerca de las secuelas causadas por esta enfermedad, la necesidad de seguimiento y requerimientos de rehabilitación. 
Carolina Carrara [ Servicio de Medicina Familiar y Comunitaria, Hospital Italiano de Buenos Aires. carolina.carrara@hospitalitaliano.org.ar ]

Carrara C. Persistencia de síntomas en pacientes con COVID-19. Evid Actual Pract Ambul. 2020;23(3):e002083. Comentado de: Carfi A, et al. Persistent Symptoms in Patients After Acute COVID-19. JAMA. 2020 Jul 9;e2012603. PMID: 32644129

\section{Referencias}

1. Carfì A, Bernabei R, Landi F, Gemelli Against COVID-19 Post-Acute Care Study Group . Persistent Symptoms in Patients After Acute COVID-19. JAMA. 2020;p. e2012603. Available from: 10.1001/jama.2020.12603.

2. Mo X, Jian W, Su Z, et al. Abnormal pulmonary function in COVID-19 patients at time of hospital discharge. Eur Respir J. 2020;55(6):2001217. Available from: 10.1183/13993003.01217-2020.

3. You J, Zhang L, Ni-Jia-Ti M, et al. Anormal pulmonary function and residual CT abnormalities in rehabilitating COVID-19 patients after discharge. J Infect. 2020;S0163-4453(20):30382-0. Available from: 10.1016/j.jinf.2020.06.003.

4. Martín-Delgado MC, de-Lorenzo-y Mateos AG. Sobrevivir a las unidades de cuidados intensivos mirando a través de los ojos de la familia. Med Intensiva. 2017;41(8):451-453. Available from: 10.1016/j.medin.2017.02.003. 